\title{
Application of Measurement Uncertainty for Electric Motor Efficiency Evaluation
}

\author{
Li Fei $^{1, a}$, Zhang Yuanxing ${ }^{2, b}$, Li Jie ${ }^{3, c}$, Yang Xiaobin ${ }^{4, d}$, Li Taoyong ${ }^{5, e}$, \\ Shang Weili ${ }^{6, f}$ \\ ${ }^{1-3,5-6}$ China Electric Power Research Institute, Beijing, China, 100192 \\ ${ }^{4}$ Yunnan Province Power Electric Design Institute, Kunming, China, 650051 \\ ayd.lifei@epri.sgcc.com.cn, ${ }^{d}$ ruben203@163.com,
}

Keywords: Electric motor, measurement, tolerance, uncertainty, efficiency.

Abstract. Faced with the challenge that resource depletion and environment deterioration, an important energy-saving measure by enhancing electric motor efficiency has been adopted around the world. With the development of measurement uncertainty of electric motor, for conventional motor efficiency evaluation, the methods or requirements used for measurement uncertainty are not uniform, and only motor tolerance is considered, how to select evaluation method to improve accuracy of electric motor efficiency has become a problem. In this paper, the theory and methods concerning measurement uncertainty of electric motor has been explored, which offer important reference for evaluation of electric motor.

\section{Introduction}

Electric motor is widely used in metallurgy, petrochemical and other industries and fields, and it causes largest electricity consumption. In recent years, in the terms of domestic and national policy, an important energy-saving measure by enhancing electric motor efficiency has been adopted around the world. Under this condition, accurate measurement for electric motor efficiency has been put on the agenda, the low measurement uncertainty for electric motor efficiency can be utilized for high efficiency and ultra-efficiency motors.

In 2012, China promulgated a new version of Evaluation and Expression of Uncertainty in Measurement. The uncertainty measurement has become one of the essential content in laboratory ${ }^{[1]}$. Meanwhile, the provisions about electric motor efficiency tolerance have been made in GB755-2008, Quota and Performance of Rotary Motor. For conventional motor efficiency evaluation, the methods or requirements used for measurement uncertainty are not uniform, and only motor tolerance is considered, how to select evaluation method to improve accuracy of electric motor efficiency has become a problem. In this paper, the theory and methods concerning measurement uncertainty of electric motor has been explored, which offer important reference for evaluation of electric motor.

\section{Measurement uncertainty and tolerance}

According to the definition of JJF 1001-2011, General measurement terms and definitions, uncertainty, a non-negative parameter, is characteristic of the dispersion of the testing parameter value. An integrated testing value should include measurement uncertainty represented by the standard deviation, which is the standard uncertainty. Under specified testing condition, the method that measurement uncertainty obtained by statistical analysis is A method evaluation, and the uncertainty can be represented with $u_{\mathrm{A}}$; the measurement uncertainty obtained by the different from $\mathrm{A}$ method evaluation is evaluation of $\mathrm{B}$ type, which can be represented with $u_{\mathrm{B}}$. B method evaluation is evaluated by testing and other relative information, which comprises subjective identification component ${ }^{[3-5]}$. The standard uncertainty of each input parameter in one testing model can be composed, and represents with $u_{\mathrm{C}}$, which is called composite standard uncertainty. Composite standard uncertainty is still of standard deviation, and be characteristic of the dispersion of measurement results. 
An expanded uncertainty $U$ is equivalent to coverage coefficient $k$ multiply composite standard uncertainty $u_{\mathrm{C}}$, namely $U=k \cdot u_{\mathrm{C}}$. In most cases, $k=2$, thus the confidence interval of $U$ is approximately half width of $95 \%{ }^{[6-8]}$.

The definition of tolerance based on GB755-2008 is that the allowable deviation between nominal value and measured value. Tolerance can be interpreted as allowable deviation for measured value, considering the impact on motor inherent performance and measured value caused by fluctuation and inconsistency of raw material performance, processing error and measurement error, and it can be expressed by percentage.

\section{Mathematical model of efficiency measurement for motor}

According to the formula of efficiency

$$
\eta=\frac{P_{2}}{P_{1}} \times 100 \%
$$

In formula: $P_{1}$-input power;

$P_{2}$ - output power, $P_{2}=P_{1}-P_{\mathrm{T}}, P_{\mathrm{T}}=P_{\mathrm{fw}}+P_{\mathrm{Fe}}+P_{\mathrm{s}}+P_{\text {culs }}+P_{\text {cu2s }}$.

Therefore, the formula of efficiency can be expressed as follows:

$$
\eta=\frac{1}{P_{1}}\left(P_{1}-P_{c u 1 s}-P_{F e}-P_{f w}-P_{c u 2 s}-P_{s}\right) \times 100 \%
$$

As can be seen above the equation, there exists 6 input items, namely, $P_{1} 、 P_{\mathrm{cu} 1} 、 P_{\mathrm{Fe}} 、 P_{\mathrm{fw}} 、 P_{\mathrm{cu} 2 \mathrm{~s}}$ 、 $P_{\mathrm{s}}$. The effect on measurement uncertainty which may bring out by other influent factors, such as equipments, researchers, and environment, should be analyzed in the measurement progress of $P_{\mathrm{cul}}$ 、 $P_{\mathrm{Fe}} 、 P_{\mathrm{fw}} 、 P_{\mathrm{cu} 2 \mathrm{~s}} 、 P_{\mathrm{s}}$. The factors which affect uncertainty of loss can be evaluated with $\mathrm{B}$ method evaluation.

According to analysis result, impact on uncertainty caused by thermal terminal resistance, wind abrasion, iron loss and stray losses which are obtained through least square method is least, which can be ignored.

\section{Repetitions with a method evaluation for measurement uncertainty}

Under the same measurement conditions, i.e., the same measurement procedure, operator, operating conditions, and the same locations, 6 times efficiency testing have been made respectively on the same motor, and the calculation result is shown in Table 1.

Table 1 The calculation result of 6 times testing

\begin{tabular}{|l|c|c|c|c|c|c|}
\hline NO. & 1 & 2 & 3 & 4 & 5 & Average \\
\hline$\eta(\%)$ & 85.70 & 85.65 & 85.71 & 85.81 & 85.78 & \multirow{2}{*}{85.62} \\
\cline { 1 - 6 } NO. & 6 & 7 & 8 & 9 & 10 & \multirow{2}{*}{$\eta(\%)$} \\
\cline { 1 - 6 } & 85.52 & 85.40 & 85.53 & 85.42 & 85.72 & \\
\hline
\end{tabular}

According to the Bessel equation, the standard deviation of the measured values of efficiency as follows:

$$
s(\eta)=\sqrt{\frac{1}{n-1} \sum_{i=1}^{n}\left(\eta_{i}-\bar{\eta}\right)^{2}}=0.00147
$$

The uncertainty through repetition with A method evaluation is ${ }^{[4]}$

$$
u_{\mathrm{A}}(\eta)=s(\eta) \cdot 100 \%=0.147 \%
$$




\section{B Method evaluation for measurement uncertainty}

\section{Uncertainty of each direct measurement parameter}

\section{Temperature logging device}

Temperature $\theta$ : when $U=0.02{ }^{\circ} \mathrm{C}, k=2$, and the measurement temperature is $100^{\circ} \mathrm{C}$, the error is $\Delta \theta=0.44^{\circ} \mathrm{C}$, thus the composite uncertainty is $u(\theta)=0.2542^{\circ} \mathrm{C}$.

\section{Torque and rotate speed sensor}

Rotate speed $n$ : when $U_{r e l}=0.02 \%, k=2$, and measurement speed is $3000 \mathrm{r} / \mathrm{min}$, its measurement error is $\Delta n=0.8 \mathrm{r} / \mathrm{min}$, and the composite uncertainty is $u(n)=0.508 \mathrm{r} / \mathrm{min}$.

Torque $T$ : when $U_{r e l}=0.02 \%, k=2$, and measurement torque is $40 \mathrm{~N} . \mathrm{m}$, and the reading deviation of indicator is $\Delta T=0.07 \mathrm{~N} . \mathrm{m}$, thus the composite uncertainty is $u(T)=0.0406 \mathrm{~N} . \mathrm{m}$.

\section{Power analyzer}

(1) Current uncertainty

Measurement uncertainty of current $I$ from the calibration certificate of the power meter: $U_{\text {rel }}=0.03 \%, k=2$; If automatic measurement range is used for current that the expectation value is $30 \mathrm{~A}$, the error is $\Delta I_{1}=0.0087 \mathrm{~A}$, and the uncertainty should be $u\left(I_{1}\right)=0.0067 \mathrm{~A}$.

Measurement uncertainty of voltage current $I$ from current transformer: the expectation value is $30 \mathrm{~A}$, and the error is $\Delta I_{2}=0.013 \mathrm{~A}$, thus the uncertainty is $u\left(I_{2}\right)=0.0067 \mathrm{~A}$.

Eventually, the composite uncertainty of current is $u(I)=0.0101 \mathrm{~A}$.

(2) Voltage uncertainty

Measurement uncertainty of voltage $U$ from the calibration certificate of the power meter: $U_{\text {rel }}=0.01 \%, k=2$; If automatic measurement range is used for voltage that the expectation value is $380 \mathrm{~V}$, the error is $\Delta U=0.0257 \mathrm{~V}$, and the composite uncertainty should be $u(U)=0.0241 \mathrm{~V}$.

(3) Power uncertainty

Measurement uncertainty of AC active power from the calibration certificate of the power meter: when $U_{\text {rel }}=0.03 \%, k=2, U=380 \mathrm{~V}, I=30 \mathrm{~A}$, and $\mathrm{PF}=0.5 \mathrm{~L}$, the error is $\Delta P=1.8 \mathrm{~W}$, and the composite uncertainty should be $u(P)=1.3457 \mathrm{~W}$.

\section{Resistance uncertainty}

When nominal value is $R=1500 \mathrm{~m} \Omega$, the tolerance is $\Delta R=0.00041 \Omega$ and the composite uncertainty should be $u(R)=0.000237 \Omega$.

Uncertainty evaluation of loss

When $y$ is determined by linear measurement function of $x_{1}, x_{2}, \ldots, x_{\mathrm{N}}$, the estimated value of $y$ can be expressed as follow:

$$
y=f\left(x,, x_{2}, \ldots, x_{N}\right)
$$

When the correlation coefficient of each input items is zero, the composite uncertainty of $y$ can be represented with $u_{\mathrm{c}}(y)$.

$$
u_{\mathrm{c}}^{2}(y)=\sum_{i=1}^{N}\left[\frac{\partial f}{\partial x_{i}}\right]^{2} u^{2}\left(x_{i}\right)
$$

\section{Uncertainty of stator copper loss under Specified temperature}

(1) Uncertainty of initial cold terminal resistance of stator winding

Cold stator winding resistance is calculated as follows:

$$
R_{1}=\left(\begin{array}{l}
R_{U V 1}+R_{U V 2}+R_{U V 3} \\
+R_{V W 1}+R_{V W 2}+R_{V W 3} \\
+R_{W U 1}+R_{W U 2}+R_{W U 3}
\end{array}\right) / 9
$$

In the progress of testing, take cold resistance of winding as $R_{\mathrm{c}}=R_{1}$, cold temperature of winding $\theta_{\mathrm{c}}=\theta_{1}, \theta_{1}$ should be the maximum among the three test points. Thus, the square of uncertainty for stator cold resistance and wind temperature are as follows: 


$$
\begin{aligned}
& u\left(R_{1}\right)=0.0790 \Omega \\
& u\left(\theta_{1}\right)=0.2542^{\circ} \mathrm{C}
\end{aligned}
$$

(2) Uncertainty of thermal terminal resistance

Due to $R_{\mathrm{w}}$ is obtained by fitting with least square method, the uncertainty of curve fitting can be ignored. Therefore

$$
U\left(R_{w}\right)=U(R)=2.37 \times 10^{-4} \Omega
$$

Winding cold resistance is $R_{\mathrm{c}}=R_{1}$, winding cold temperature is $\theta_{\mathrm{c}}=\theta_{1}$.

(3) Uncertainty of winding operating temperature

Winding temperature $\theta_{\mathrm{w}}$ is determined by thermal terminal resistance $R_{\mathrm{w}}$, and the formula is

$$
\theta_{w}=\frac{R_{W}}{R_{C}} \times\left(K_{1}+\theta_{c}\right)-K_{1}
$$

Therefore, the squared of operating temperature uncertainty of stator winding is $u\left(\theta_{w}\right)=0.3350^{\circ} \mathrm{C}$.

(4) Uncertainty of specified temperature of stator

The specified temperature $\theta_{\mathrm{s}}$ can be calculated as

$$
\theta_{s}=\theta_{w}+25-\theta_{b}
$$

The squared of specified temperature uncertainty is $u\left(\theta_{s}\right)=0.4205^{\circ} \mathrm{C}$.

(5) Stator cooper loss uncertainty under specified temperature

The formula of winding resistance under specified temperature is

$$
R_{s}=R_{1} \times \frac{K_{1}+\theta_{s}}{K_{1}+\theta_{1}}
$$

The squared of winding resistance uncertainty under specified temperature is $u\left(R_{s}\right)=2.088 \times 10^{-3} \Omega$.

The stator copper loss under specified temperature can be expressed as

$$
P_{c u l s}=1.5 I_{1}^{2} R_{s}
$$

Therefore, the uncertainty of stator copper loss under specified temperature is $u\left(P_{c u l s}\right)=0.5764 \mathrm{~W}$

\section{The uncertainty of other parameters}

(1)Under the condition that ignoring the impact on uncertainty of curve fitting for wind abrasion, whose uncertainty is comprised by the uncertainty of constant loss and winding resistance.

$$
u\left(P_{f w}\right)=u\left(P_{c o n}\right)=1.3545 \mathrm{~W}
$$

(2) Ignoring the impact on uncertainty of curve fitting for iron loss, whose uncertainty is comprised by the uncertainty of constant loss and wind abrasion.

$$
u\left(P_{f e}\right)=\sqrt{u^{2}\left(P_{c o n}\right)+u^{2}\left(P_{f w}\right)}=1.9156 \mathrm{~W}
$$

(3) According to the same analysis above, the uncertainty of other parameters are as follows:

1) Rotor copper uncertainty under specified temperature

$$
u\left(P_{c u 2 s}\right)=1.2359 \mathrm{~W}
$$

2) Ignoring the impact on uncertainty of curve fitting for residual loss, stray loss uncertainty is ${ }^{[5]}$

$$
u\left(P_{s}\right)=\sqrt{4 a^{2} T^{2} u^{2}(T)}=1.6514 \mathrm{~W}
$$

\section{Uncertainty of apparent total loss}

Apparent total loss is calculated as follows:

$$
P_{T}=P_{f w}+P_{F e}+P_{s}+P_{c u 1 s}+P_{c u 2 s}
$$

Thus, the squared of Apparent total loss uncertainty is 


$$
u^{2}\left(P_{T}\right)=u^{2}\left(P_{f w}\right)+u^{2}\left(P_{F e}\right)+u^{2}\left(P_{s}\right)+u^{2}\left(P_{a 1 s}\right)+u^{2}\left(P_{c u 2 s}\right)=14.2774 \mathrm{~W}
$$

\section{Uncertainty of efficiency}

Efficiency is calculated as

$$
\eta=\frac{P_{2}}{P_{1}}=\frac{P_{1}-P_{T}}{P_{1}} \times 100 \%
$$

The uncertainty of efficiency evaluated by B method evaluation is

$$
u_{\mathrm{B}}(\eta)=\frac{1}{P_{1}} \sqrt{u^{2}\left(P_{T}\right)+\left(\frac{P_{T}}{P 1} u\left(P_{1}\right)\right)^{2}} \times 100 \%=0.0375 \%
$$

\section{Composite standard uncertainty}

Refer to the formula of composite uncertainty

$$
u_{C}(\eta)=\sqrt{u_{A}(\eta)^{2}+u_{B}(\eta)^{2}}=0.15 \%
$$

The system expanded uncertainty can be obtained $U=k u_{\mathrm{C}}(\eta)=0.30 \%$, where $k=2$.

\section{Energy efficiency uncertainty and tolerance of motor}

JJF1094-2002 stipulates that when MPEV (ratio of absolute value of indication error uncertainty $U_{95}$ and maximum allowable error of measurement devices) is less than $\frac{1}{3}$, thus indicator error uncertainty can be ignored in efficiency testing.

From the results can be seen: the motor efficiency expanded uncertainty is $0.30 \%$, and it's relatively small. For $7.5 \mathrm{~kW}, 8$-pole electric motor, its efficiency can be evaluated through 6 levels evaluation regulation, thus the efficiency level is 3 , and corresponding efficiency tolerance is $1.92 \%$, it can deducted that the efficiency expanded uncertainty is less than $\frac{1}{3}$ times of efficiency tolerance.

Meanwhile, a segment sampling verification range from $0.75 \mathrm{~kW}$ to $375 \mathrm{~kW}$ electric motor has been made, including $7.5 \mathrm{~kW}, 2$-pole motor; $14 \mathrm{~kW}$, 4-pole motor, $55 \mathrm{~kW}$, 4-pole motor, $315 \mathrm{~kW}, 4$-pole motor. The testing results are in consistent of $7.5 \mathrm{~kW}, 8$-pole motor, the measurement uncertainty of all the testing motors is less than $\frac{1}{3}$ times of efficiency tolerance. The testing results are shown in table 2.

Therefore, if measurement uncertainty value is less than $\frac{1}{3}$ times of efficiency tolerance, uncertainty can be ignored in evaluation process, and if measured value is located in the following range, the measured is qualified.

(1) Measured value $\geq$ energy efficiency limited value + efficiency tolerance

(2) Marked value $\geq$ label value + efficiency tolerance 
Table 2 Evaluation results concerning energy efficiency uncertainty of low voltage three-phase inductor motor

\begin{tabular}{|c|c|c|c|c|c|c|c|}
\hline \multirow{4}{*}{ Capacity } & \multicolumn{2}{|c|}{\begin{tabular}{|c|}
$\begin{array}{c}\text { Energy efficiency } \\
\text { level }\end{array}$ \\
\end{tabular}} & \multicolumn{2}{|c|}{$\begin{array}{c}\text { Energy efficiency } \\
\text { level }\end{array}$} & \multicolumn{2}{|c|}{$\begin{array}{c}\text { Energy efficiency } \\
\text { level }\end{array}$} & \multirow{4}{*}{$\begin{array}{l}\text { Expanded } \\
\text { uncertainty } \\
\quad(\mathrm{k}=2)\end{array}$} \\
\hline & 2 & 3 & 2 & 3 & 2 & 3 & \\
\hline & \multicolumn{2}{|c|}{ Pole } & \multirow{2}{*}{\multicolumn{2}{|c|}{\begin{tabular}{|c|} 
Efficiency tolerance \\
2-nole
\end{tabular}}} & \multicolumn{2}{|c|}{ 1/3times of tolerance } & \\
\hline & 2 & 2 & & & \multicolumn{2}{|c|}{ 2-pole } & \\
\hline 7.5 & 90.1 & 88.1 & $1.49 \%$ & $1.79 \%$ & $0.50 \%$ & $0.60 \%$ & $0.54 \%$ \\
\hline \multirow{4}{*}{ Capacity } & \multicolumn{2}{|c|}{\begin{tabular}{|c|}
$\begin{array}{c}\text { Energy efficiency } \\
\text { level }\end{array}$ \\
\end{tabular}} & \multicolumn{2}{|c|}{$\begin{array}{c}\text { Energy efficiency } \\
\text { level }\end{array}$} & \multicolumn{2}{|c|}{$\begin{array}{c}\text { Energy efficiency } \\
\text { level }\end{array}$} & \multirow{4}{*}{$\begin{array}{l}\text { Expanded } \\
\text { uncertainty } \\
\quad(\mathrm{k}=2)\end{array}$} \\
\hline & 2 & 3 & 2 & 3 & 2 & 3 & \\
\hline & \multicolumn{2}{|c|}{ Pole } & \multirow{2}{*}{\multicolumn{2}{|c|}{\begin{tabular}{|c|} 
Efficiency tolerance \\
4-pole
\end{tabular}}} & \multicolumn{2}{|c|}{$1 / 3$ times of tolerance } & \\
\hline & 4 & 4 & & & \multicolumn{2}{|c|}{ 4-pole } & \\
\hline 14 & 91.8 & 90.2 & $1.24 \%$ & $1.47 \%$ & $0.41 \%$ & $0.49 \%$ & $0.16 \%$ \\
\hline 55 & 94.6 & 93.5 & $0.81 \%$ & $0.98 \%$ & $0.27 \%$ & $0.33 \%$ & $0.28 \%$ \\
\hline 315 & 96.0 & 95.1 & $0.40 \%$ & $0.49 \%$ & $0.13 \%$ & $0.16 \%$ & $0.13 \%$ \\
\hline \multirow{4}{*}{ Capacity } & \multicolumn{2}{|c|}{\begin{tabular}{|c|}
$\begin{array}{c}\text { Energy efficiency } \\
\text { level }\end{array}$ \\
\end{tabular}} & \multicolumn{2}{|c|}{$\begin{array}{c}\text { Energy efficiency } \\
\text { level }\end{array}$} & \multicolumn{2}{|c|}{$\begin{array}{c}\text { Energy efficiency } \\
\text { level }\end{array}$} & \multirow{4}{*}{$\begin{array}{l}\text { Expanded } \\
\text { uncertainty } \\
\quad(\mathrm{k}=2)\end{array}$} \\
\hline & 2 & 3 & 2 & 3 & 2 & 3 & \\
\hline & \multicolumn{2}{|c|}{ Pole } & \multirow{2}{*}{\multicolumn{2}{|c|}{\begin{tabular}{|c|} 
Efficiency tolerance \\
6-pole
\end{tabular}}} & \multicolumn{2}{|c|}{ 1/3times of tolerance } & \\
\hline & 6 & 6 & & & \multicolumn{2}{|c|}{ 6-pole } & \\
\hline 7.5 & 89.1 & 87.2 & $1.64 \%$ & $1.92 \%$ & $0.55 \%$ & $0.64 \%$ & $0.30 \%$ \\
\hline
\end{tabular}

\section{Conclusion}

Several factors corresponding to electric motor energy efficiency has been analyzed in this paper. Uncertainty of each factor has been calculated to get composite uncertainty, and energy efficiency expanded uncertainty of each factor has finally obtained. Compared with expanded uncertainty and efficiency tolerance, the results of analysis are as followings:

(1) There is impact on energy efficiency uncertainty caused by each loss factor, where uncertainty caused by stray loss is the most complex.

(2) Under the testing condition of GB1032-2012, all the energy efficiency uncertainty referred in this paper is less than $\frac{1}{3}$ times of efficiency tolerance.

(3) If measurement uncertainty is less than $\frac{1}{3}$ times of efficiency tolerance, in the process of energy efficiency evaluation, measurement uncertainty can be ignored.

The theory analyzed in this paper provides vital reference for energy efficiency uncertainty of electric motor, which can be utilized for qualification and energy efficiency evaluation of electric motor, and it make sense for improving electric motor efficiency

\section{References}

[1] JNational Technical Committee of Legal Metrology Metering Management .JJF 1059.1-2012 Evaluation and Expression of Uncertainty in Measurement [S] Beijing: China Quality Inspection Publishing House, (2012).

[2] National Standardization Technical Committee of Rotary Motor .GB/T1032-2012 Testing method for Asynchronous motors [S] Beijing: China Standardization Publishing House, (2012).

[3] National Technical Committee of Legal Metrology Metering Management, JJF 1001-2011, Common Terms and Definitions of Measurement [S]. Beijing: China Standard Press, (2011). 
[4] National Foundation and Management Standardization Technical Committee of Energy 18613-2012 GB, Small and Medium Three-phase Asynchronous Motors of Energy Efficiency and Energy Efficiency Level limited Value [S]. Beijing: China Standardization Press, (2012)

[5] P National Standardization Technical Committee of rotary motor .GB 755-2008 Quota and Performance of rotary motor [S]. Beijing: China Standardization Press, (2008)

[6] Ni Yucai, Practical Uncertainty Evaluation [M]; Beijing. China Quality Inspection Press, (2014)

[7] Wang Chuanjun, Uncertainty Evaluation Concerning Stray Loss of Three-phase Induction Motor [J] Motor \& Control Application, ( 2011)

[8] Wang Chuanjun, Jin Zhiwei, Chen Gen, ect., Research and Design of Uncertainty Testing System for High Efficiency and Ultra-efficiency Motor [J] Motor \& Control Application, (2010). 